The Philosophical Journal of Conflict and Violence

Vol. II, Issue 2/2018

(C) The Authors 2018

Available online at http://trivent-publishing.eu/

\title{
The Gentle Way \\ Maximising Efficacy and Minimizing Violence in Judo
}

\author{
Dario Mazzola \\ Department of Philosophy, University of Milan, Italy, dario.mazzola@unimi.it
}

\begin{abstract}
This paper explores the way violence is understood and controlled in judo. The analysis is based on historical sources and classic principles of the martial art as well as in the regulations and official guidelines of the main institutions governing sportive judo. The focus is on the apparent tension between the principle of "maximum efficacy" (Seiryoku-Zenyo) and the way violence is addressed at no less than three levels: in sparring and competition, in teaching and training, and in society at large. The conclusion being the claim: judo is a "non-violent martial art”.
\end{abstract}

Keywords: Norbert Elias; Jita-Kyoei; Judo; Martial Arts; Maximum Efficacy; Mutual Prosperity; Seiryoku-Zenyo; Violence.

\section{TRIVENT}

The PJCV Journal is published by Trivent Publishing.

This is an Open Access article distributed in accordance with the Creative Commons Attribution Non Commercial (CC-BY-NC-ND 4.0) license, which permits others to copy or share the article, provided original work is properly cited and that this is not done for commercial purposes. Users may not remix, transform, or build upon the material and may not distribute the modified material (http:/ / creativecommons.org/ licenses/by-nc/4.0/) 


\title{
The Gentle Way: Maximising Efficacy and Minimizing Violence in Judo
}

\author{
Dario Mazzola \\ Department of Philosophy, University of Milan, Italy, \\ dario.mazzola@unimi.it
}

\begin{abstract}
This paper explores the way violence is understood and controlled in judo. The analysis is based on historical sources and classic principles of the martial art as well as in the regulations and official guidelines of the main institutions governing sportive judo. The focus is on the apparent tension between the principle of "maximum efficacy" (Seiryoku-Zenyo) and the way violence is addressed at no less than three levels: in sparring and competition, in teaching and training, and in society at large. The conclusion being the claim: judo is a "non-violent martial art”.
\end{abstract}

Keywords: Norbert Elias; Jita-Kyoei; Judo; Martial Arts; Maximum Efficacy; Mutual Prosperity; Seiryoku-Zenyo; Violence.

\section{Introduction: On Gold and Hard Rock Mining}

The eyes of an unhabituated spectator would likely be stunned by the contrasting and barely distinguishable dynamics of chaos and patterns of formalized order which bring together judokas (judo practitioners) in the Scampia dojo (gym). The vigorous, neat instructions by master Pino Maddaloni are followed by their frantic application in swirls of grip fighting, off-balancing, and throws. His controlled voice offers detailed descriptions of the slightest body movement to be executed to minimize consumption of strength and effort while maximizing the likelihood of projecting. Then, it fades intermittently into the bangs of dozens of judokas throwing each other to the rhythm of a crazy drummer. The playing ground and equipment are simple and tidy: a flat mat trod on by girls and boys in invariably white and standard-length suits, sometimes differentiated by minuscule changes in logo only. Yet the body movements of fighters are fanciful, and the unforeseeable trajectory of each sparring couple is sometimes marked by sweat dropping. Once again, an unhabituated spectator would look quite puzzled when told that this spectacle is an education into order, discipline, respect of others, and non-violence.

However, a more expert visitor would easily recognize the differences between the Star Judo Club and the surrounding Neapolitan outskirt. Despite all the fighting and commotion, the dojo has unchallengeable rules, limits, and authorities, ranging from the old, elegant Japanese man overlooking the practitioners in a black-and-white picture, to the vigorous master who knows how to discipline even the most reluctant disciples-without beating them, of course. This universe of chaotic movements is animated and stopped by the omnipotent words hajime (go!) and mate (stop): no one attacks or moves before or after these commands. The very mat is circumscribed by a red square, whose sight slows down 
and arrests the fighters, but the very horizon of this world is constituted by the moments of rei (salute, but also "respect", "etiquette", or "expression of gratitude"), when practitioners and masters, facing each other, bow at the same moment.

Outside the dojo, both appearances and reality differ. Granted, it is quite improbable to see someone strangling or applying an arm bar on the streets, just as it is to see people crawl or somersault on the ground. But the deep social dynamics might be more disordered than it seems: Scampia is a poor neighborhood where local mafia has taken deep roots, and where it recruits youth for drug-dealing and other such activities. During the Scampia feud, a fight between rival clans which reached its height in the years 2004-2005, about 70 people were murdered, including some innocents targeted mistakenly, or on purpose. In this setting, master Maddaloni's explicit invitation to avoid and fight the mafia does not sound as cheap as it would do elsewhere. Maddaloni knows what he is talking about: himself born in Scampia, he found in judo an alternative to street violence, as had his father and coach Gianni. Pino devoted all his energy to it, to the point of winning the Olympic Gold at the Sydney 2000 games in the 73-kg weight category.

The point of his story and of the related movie ${ }^{1}$ is that, like mining, judo consists in the tiring and relentless search and transformation of human nature to extract from violent impulses and disordered tendencies of a sociable character and forge it to serve one's wellbeing and community. In this paper, I will try to make sense of this very ambitious and hardly defined claim, analytically and scientifically.

I will proceed as follows: in a first section, I will introduce some cultural and historical elements on Japanese martial arts and judo in particular. I will devote substantial attention to the founding principles of judo as defined by its inventor and presented by the main official institutions in charge of defending and furthering it. I will then show how the relation and tension between efficacy and violence is composed and addressed in the principles and practice of judo, especially by making reference to studies on the effects of judo practice on bodily health and behaviour. In the lights of these findings, I will finally draw conclusions on the correspondence of judo to the model elaborated by Norbert Elias and Eric Dunning, and on the intrinsic coherence and factual accuracy of judo's ideology and practices.

\section{Background}

\section{A. Japanese Martial Arts: History and Culture}

Forms of fighting, including ceremonial and symbolic fighting, are extremely widespread if not universal in human societies. Therefore, the process of civilization and modernization, in association with globalization, have brought to the fore a plethora of fighting sports whose origins are to be traced in as many local cultures and societies. At first sight, martial arts and fighting sports are not so easily distinguished, and much of the difference hinges on the way they are practiced.

However, in the established usage described by the Oxford English Dictionary (OED) martial arts are "Various sports, which originated chiefly in Japan, Korea, and China as forms of self-defense or attack, such as judo, karate, and kendo." Here "arts" and "sports" are considered synonymous, which will offer grounds for reflection at a later stage. Although, another relevant aspect of the OED definition is that it confines the phrase to practices "chiefly" coming from the Far East: thus, in order to understand judo, it is mainly Japanese history and culture that needs being briefly mentionned, even if the importance of mutual relations between Japan, Korea, China, and, anciently, India, is now widely

\footnotetext{
${ }^{1}$ Marco Pontecorvo, L'oro di Scampia (The gold of Scampia), Rome, Rai Cinema, 2014. The movie is based on Gianni Maddaloni, La mia vita sportiva (My sporting life), (Milano: La Comune, 2010).
} 
acknowledged $^{2}$. That is why virtually every judo handbook or publication on the subject includes a section on the history of judo's country of origin.

Japanese history is permeated by stories of wars, battles, and fights, even in its mythical beginnings: indeed, according to ancient chronicles, the couple of male and female gods and progenitors, Izanagi and Izanami, would have generated the Japanese archipelago by letting drops of water pour from Izanagi's spear. In a following episode in this saga of Shinto, Japan's national religion, the sun goddess Amaterasu, mother of the imperial family, is presented a sword as a sign of sorrow and pacification by her bellicose brother Susanoo, whose unruly behaviour had made her move into a cave, thus plunging the universe into darkness ${ }^{3}$.

These stories mirror the historical realities they originated from. The unity and homogeneity of the Japanese people, embodied in the Emperor and in his cult, was tempered by the geographical and political fragmentation of the archipelago, divided into a multitude of warring clans. Thus, while formally subordinated to the Emperor, the shogun ("general": abbreviated for Seï Tai Shogun "most illustrious general that subdues the

2 Allen Barry, Striking Beanty: A Philosophical Look at the Asian Martial Arts (New York: Columbia University Press, 2015), 25. Barry claims that the founder of judo denied all Chinese influence on it, but from the source he relies on it appears that Jigoro Kano's opinion is nuanced and complex: "We believe then that jujutsu is a Japanese art, which could have been developed to its present perfection without any aid from China, although we admit that Chingempin, or some Chinese book in kenpo may have given a stimulus to its development." See Jigoro Kano, "Jujitsu and the origin of judo," trans. Thomas Lindsay, Transactions of the Asiatic Society of Japan 15 (1887) republished on Judo Info Online Dojo: http://judoinfo.com/kano6/ (accessed May 20, 2018). The story of the Chinese Chingempin importing elements of martial arts to Japan is also confirmed in Martial Arts of the World: An Encyclopedia. Volume I, ed. Thomas Green, (Santa Barbara, Denver and London: ABC-CLIO, 2001), 201. According to the International Judo Federation (IJF) official website: "Very early in Kano's rigorous education Western influences were added to Eastern traditions and teachings. One of his grandfathers was a well-known poet and a scholar of Chinese.", in "KANO and the Beginning of the Judo Movement," https://www.ijf.org/history/judo-corner (accessed June 4, 2018). A deep casestudy scholarly research on the influence of Chinese martial arts on one kata (form) of judo is presented in Chang Liu, Kyungwon Jung, Fumiaki Shishida, “A Technical analysis of Seiryoku zen'yo Kokumin taiiku - From a Karate and Chinese martial arts perspective as it affected Kano Jigoro," Journal of Martial Arts Anthropology 16/1 (2016): 1-10.

3 See Part one of Kenneth Henshall, A History of Japan: From Stone Age to Superpower (London: Palgrave Macmillan, 2012). Other sources for this historical section are books by Leonardo Vittorio Arena: from the beginnings to the Meiji revolution (or "restauration"): Samurai: Ascesa e declino di una grande casta di guerrieri ["Samurai: Rise and Decline of a Great Warrior Caste”] (Milan: Mondadori, 2002); on Japanese Fascism and World War II: Kamikaze: The Epic of Suicidal Warriors (Milan: Mondadori, 2003); on the samurai caste Il pennello e la spada: la via del samurai ["The Brush and the Sword: The Way of the Samurai] (Mondadori: Milan, 2013). A more synthetic account is to be found in Kevin Gray Carr, "Making Way: War, Philosophy and Sport in Japanese Judo," Journal of Sport History 20/2 (1993): 167188. Both on samurai military ethics (bushido, "the way of the warrior") in general and on martial arts and judo moral principles more particularly, Carr takes a debunking and critical perspective. This has obviously some merits, but I think the claims that bushido was an ideological cover which was mostly elaborated in recent times fails to match with the functions it repeatedly performed in Japanese history. For instance, it is difficult to reconcile the self-interested behavior attributed to warriors of the classic period with the institute of seppuku, the ritual suicide which followed defeat but was also required as a form of honor-restoring self-punishment by feudal lords. Carr also claims that an amoral stance would be mirrored by contemporary competitive judo, but IJF, Kodokan, and other official institutions' regulations hold decisively that sportive judo is a coherent development of Kano's creation. Also, several aspects of Carr's critiques seem to oversimplify the relation between jutsu/waza (art/technique) and $d o$ (way, especially in the sense of "moral code") by presenting them as purely contradictory. While acknowledging the import of Carr's contribution and of the problems it discusses, I would hold that reality is more complex. 
barbarians") established a growing centralized control over the country and commanded a military caste. Thus the samurai (literally "servants") dominated Japan first by military and then by administrative power. With the firm establishment of the Tokugawa as a ruling dynasty, the failures of attempted invasions of the Asian continent, and the expulsion of almost all foreigners according to a policy of closure (sakoku, "closed country"), the end of the sengoku jidai ("age of warring states") implied the absence of any enemy, and Japanese martial culture began a period of unique and separated self-reflection, transformation, ritualization and formalization.

This history was at a time continued and revolutionized when US commodore Matthew C. Perry, having received the mandate to open the country to US commerce and having studied Japanese history and culture, persuaded the bakufu ("military government," literally, "government in the camp tent") to receive his embassy by the diplomatic language a caste of warriors could most easily understand: cannon fire and the menace of destruction. Thus, in 1853, ends the Tokugawa period and begins the Meiji ("enlightened") era, in which the Emperor took power back in his divine hands after centuries of delegated administration by the shogun, and did so to respond to the unprecedented threat of Japan being drawn from its sovereign isolation into colonization. The samurai and all other castes were officially abolished: sciences, industry, education, administration, military, and other governmental fields were quickly modelled after the most powerful Western nations, whose influence the Emperor was eager to acquire and use to reign.

Japan initiated an aggressive foreign policy: expansion abroad led soon to war with Russia and conflicts with the Society of Nations, from which Japan withdrew in 1933 in response to the unanimous condemnation of the invasion of Manchuria. The country's military tradition was inflamed by world events, and once again the imperial government was gradually transformed into a regime controlled by the armed forces, called Tennosei fashizumu ("fascism under command of the Son of Heaven"): alliance with the Axis and another clash with the US in the Pacific Ocean were inevitable. Japan exited the war materially and culturally shocked, with the atomic bombings of two main cities and the imperial declaration of humanity, advanced by Hirohito at the request of the occupying forces.

Another period of rapid and radical modernization ensued, this time of a passive and internationalist kind: Japan renounced to possessing a full-fledged military in Article 9 of its Constitution, and martial arts, after a period of abandonment due to prohibitions by the Allies, were surprisingly transformed into a matter of interest for foreigners and a language of communication for internationalization.

Today, martial traditions and sports of a now peaceful Japan are among its universally admired hallmarks, together with high-tech brands, sushi, and many others.

\section{B. The History of Judo and of its Founder}

It is within the defined boundaries of this national and, from some point on, international history that we see the history of Kodokan Judo, the founding institution of modern judo. In this history, we notice an exceptional role is played by the individual personality of Jigoro Kano, whose biography is included in most judo handbooks, and accordingly so ${ }^{4}$.

\footnotetext{
4 Jigoro Kano, Kodokan Judo (London, New York, Tokyo: Kodansha International, 1986). In the foreword, Jigoro's grandson and then Kodokan president, Yukimitsu Kano, epitomizes that "To speak of judo is to speak of Jigoro Kano. To hear the name of Jigoro Kano is to be reminded of the Kodokan." (11). The nexus between the founder (and his family and disciples), the institution, the sport, the martial art, is evidently the strongest possible. Besides this, my sources on the life of Kano and on the foundation of Kodokan include Kyuzo Mifune, Canon of Judo (Tokyo: Seibundo-Shinkosha Publishing and Co., 1958) and materials drawn from the IJF and the Kodokan official websites :
} 
Kano was born on 28 October 1860, only a few years after Perry's cannons had opened Japan, in a rich and aristocratic family. Kano himself was a brilliant student, but also a boy of a weak and thin bodily constitution. The combination of these exposed him to harsh bullying in schools, beginning from an early age. In this, the life of the noble, educated, fine intellectual, humanist, and polymath Kano converged with those of the stereotypical representatives of fighting sports in contemporary age, such as Mike Tyson and Sebastian Rutten. Kano, as the others, reacted to bullies and humiliation by working on "supercompensation," the core principle of all sport training, for his physical inferiority. Although, according to Kano, supercompensation was not to be limited to growing muscles: it was a spiritual task.

Starting was not easy, given Kano's social position. Martial arts had represented the pride of the warriors until the end of the Tokugawa era, but were then already considered a relic of a distant, chaotic past. In late nineteenth century they were even more discarded by the abolition of the samurai class and by the hasty attempt at concealing everything Japanese from the mocking regards of foreigners. Thus, masters of old jujitsu (gentle art) combat styles hid their pedigrees or sold it out in ways which were considered dishonourable, such as by offering public shows and fighting with sumo players. Others used the knowledge of human anatomy and therapeutic moves required by jujitsu and reemployed themselves as bonesetters. It is to these latter that Kano secretly turned, without any help by his aristocratic family. However, since the masters themselves were also unpersuaded to give what was now considered brutal and vulgar fighting education to a scion of the nobles, Kano had to wait years, and to show exceptional perseverance, before being able to train systematically in jujitsu.

While studying at Tokyo Imperial University (now simply Tokyo University), Kano learned the Tenjin Shinyo-ryu ("school of the heart of the willow") style of jujitsu under the direction of master Hachinosuke Fukuda. At Fukuda's death, after receiving the scrolls containing the principles of the school, he continued to study with master Iso Masatomo, and at a later stage he entered the Kito Ryu ("school of light and darkness") directed by master Iikubo Kohei. At the age of 21, Kano witnessed a demonstration by master Ichimon Totsuka at the Tokyo Imperial University hall. He then became persuaded that every jujitsu school of the 179 officially recognized had unique strength and weaknesses, and that to establish one's own effective style one had to travel, discuss, and study them all.

With a curriculum that finally enabled him to found his own school, Kano moved on to the Eishoji Buddhist temple, where he established his first training centre, although a very small one. It was in 1882, the year of birth of the Judo Kodokan ("the school where the way is studied"). The school had to move frequently in the following years since space and resources were still relatively precarious and scarce: at 27 , Kano finally received a fund by a nobleman with an interest in judo and in his pedagogics, which permitted the opening of more spacious dojos. However, it was only in 1934 that the Kodokan moved to the place where the institute is today.

The acquisition of resources and popularity was not the result of sheer luck: by participating in public tournaments organized by the Tokyo Metropolitan Police, Kano demonstrated that his disciples were often victorious over other styles of jujitsu. Kano did

http://kodokanjudoinstitute.org/en/doctrine/history/ (accessed June 4, 2018). Carr's "Making Way" includes a biographical sketch of Kano and notes on the foundation of judo also. I derived additional details from the Judo Channel created by the All Japan Judo Federation and the Token Corporation :http://www.judo-ch.jp/english/kanou_life/profile/index02.shtml (accessed June 4, 2018). Other sources with a great wealth of details on the life of Kano and the origins of judo are John Stevens, The Way of Judo: A Portrait of Jigoro Kano and his Disciples, (Boston and London: Shambhala, 2013); Brian N. Watson, The Father of Judo: A Biography of Jigoro Kano, (New York: Kodansha Amer. Inc., 2000); Brian N. Watson, Judo Memoirs from Jigoro Kano, (Bloomington: Trafford Publishing, 2008). 
not waste the opportunity afforded by greater popularity: he deepened all the aspects of jujitsu which were relevant to his purposes of creating a new "way". He also met with the "founding fathers" of the other main Japanese martial arts, Ueshiba Morihei for aikido and Gichin Funakoshi for Shotokan karate: Kano appreciated and encouraged both.

Kano's career as an educator and public officer surely contributed to the success and fundamental shape of judo. After graduating in literature, politics, and political economy in 1881, he taught at the important Gakushuin Institute, where the cadres of the newly modernizing Japanese empire were educated. He then founded Kobunkan, a school for Chinese students, and in 1889 was appointed to a post in the Imperial Household Department. His next career step was as principal of the Tokyo Higher Normal School. In the meanwhile, in 1909 "The Diet unanimously approved a bill requiring all middle schools to provide instruction in gekiken (free fencing) swordsmanship and jujutsu"5. In 1922, he was elected to the House of Peers.

The internationalism of judo owes much to Kano's own personality and skills: he was educated in foreign languages by native speakers of English and German since 1873, and they considered him exceptionally gifted. He knew English especially well and took many of his notes directly in this language. In 1879, together with his master Fukuda, he participated in a demonstration of Japanese martial arts before US President Ulysses Grant. In 1889 he travelled for an instructional tour in Europe. While sailing, he gave a judo demonstration to other passengers, who were amazed by how a small man could easily throw a bigger one. In 1909, he was appointed the first Japanese member of the International Olympic Committee (IOC). He then started promoting judo and, in 1928, attended the Olympic Games in Amsterdam. While coming back from the 1938 Olympic Committee in Cairo, Kano died on the Hikawa Maru ocean liner, a ship which was a vital connection between Japan and the rest of the world. It was May $4^{\text {th }}$, and his last words were: "Photographs are a good way to depict kata (form) ...". ${ }^{6}$ A suitable remark for a man whose whole life was a bridge between tradition and modernity.

Some aspects of the new-born martial arts derive naturally from the life of its father and from its context. Before considering the more specifically martial aspects, it is useful to reflect on the general feature of judo. Itself a mix of tradition and innovation, judo was born as a democratic art, open to aristocratic, commoners, and women alike. This was obviously made possible only by the specific historical situation: had Kano been born forty years before, such practices would have been restricted to samurai. Precise choices of dress-code and etiquette emphasized this unifying and equalizing element: the system of belt colors allowed for only minimal changes in appearance between low and high ranks. There are records of correspondences of the pedagogic style Kano introduced in the schools where he served, for instance his opposition to aristocratic students being carried to classes in rickshaws, who basically treated their teachers as lowly attendants.

Internationalism is also in judo's DNA. Despite insisting on the national character of jujitsu and judo, Kano opened it to foreign influences: when meeting with a partner he could not throw, Kano tried Western wrestling techniques he found in books at the library, and thus "invented", or rather "exported" kata guruma ("wheel on the shoulders", actually the fireman's carry ended with a drop) 7 . This otherwise insignificant anecdote could not have taken place if Kano had been illiterate in English, which in turn depended on the mutated conditions of the country with regards to foreign influences. In such a small episode, modernization and globalization are reflected: so was in general for Kano's

\footnotetext{
${ }^{5}$ Kano, Kodokan Judo, Appendix A, 295.

6 See page "The Death of Jigoro," on Judo Channel (already cited).

7 Brian N. Watts, Judo Memoirs from Jigoro Kano (Bloomington: Trafford Publishing, 2008), 6-7.
} 
attitude. As Damon Young says, Kano was "far more Westernized than his counterparts in Karate and Aikido"s.

The foreign influence was felt in the way judo was made scientific in a Western sense, that is, by incorporating the simplest and most general principles, and by avoiding inconsistency. Kano's thought was deeply influenced by utilitarianism, and if it sometimes parts way from it, it is true that there are strong similarities among the two philosophies? Kano's thought does not seem directly indebted to any specific version of systematic utilitarian philosophy, such as Bentham's or Mill's. Rather, it appears that the commonalities between judo's principles and utilitarianism in general lie in the attempt at rationalizing the body of an inherited tradition-be it the techniques of jujitsu or British common law-by finding an underlying rationale. Also, the teleological structure of the two philosophical enterprises seem to be analogous, with Kano evaluating every dilemma or choice over the newly established martial art by reference to its social and spiritual aims. This would somewhat mirror the maximisation of utility or happiness in opposition to deontologist thought, which in Kano's case could also be translated as vacuous and dogmatic traditionalism.

John Dewey himself visited the Kodokan in 1919, and reportedly had words of appreciation for Kano's pedagogics, saying that it deserved to be studied. Certainly, some parallels can be established between judo and pragmatism, since learning-by-doing is at the core of modern judo.

In general, and to conclude, a pronounced foreign influence, coupled with the virtues of a flexible mind, is evident in the way Kano freely elaborated jujitsu. He put every aspect of the art to a triple test constituted by 1) his own critical attitude, 2) experimentation and practice, and 3) public and open discussion. All the techniques and forms of judo are the fruits of discussions and even of commissions devoted to considering the aspects in favour or against all subtleties.

Other considerations could be added, for instance regarding the way Kano institutionalized the Kodokan by looking at the educational and administrative bodies he was himself a member of, and which he studied during his journey to Europe. Also, the admiration for the principles of Olympism, which is manifest in Kano's frequentation of Baron Pierre de Coubertin, and in this latter's choice to name Kano a member of the IOC, is relevant in showing the harmonious relations between development of judo as a sport and modern sports in general.

This story would also deserve to be made more complex and less unilateral. In fact, while the positivist atmosphere which characterized society at the time of the birth of judo encouraged the association of modernization with progress and development, we are now in a better position to recognize that modernity can have drawbacks. The "simplification" or "rationalization" of the tradition can well be seen as a loss of the tradition. The bureaucratization of the discipline can be read as an impoverishment and a distraction from its substantial values and original aims ${ }^{10}$. Organizations of various stripes often provide alternative if not utterly critical perspectives on "official" and sportive judo. For instance, the development of the belt colors system can be considered a way of introducing

\footnotetext{
8 Martial Arts and Philosophy: Beating and Notbingness, ed. Graham Priest and Demon Young (Chicago and LaSalle: Opencourt, 2010), 4.

9 Ibid., chapter 7 by Sasha Cooper and Travis Taylor, "Armbarring the Common Good".

10 See Samuel Juhle, "Les Pratiques Martiales Japonaises en France. Institutionnalisation des disciplines et professionnalisation de l'enseignement," Actes de la recherche en sciences sociales 4/179 (2009) : 92-11. Juhle's study cites some judo masters which are very critical towards the centralized and bureaucratic form judo has taken in recent years. See also Kevin Gray Carr, "Making Way: War, Philosophy and Sport in Japanese Judo". See also footnote 3.
} 
hierarchization, agonism, and bureaucratization from an early stage: Kano himself never had a precise degree, and he has been awarded an honorary $12^{\text {th }}$ Dan only posthumously.

While they should not fall out of sight, it is impossible to solve or even thoroughly treat these controversies here. However, by now we have gathered enough elements to consider the defining and central aspects of judo, and in particular those concerning the main research question over the tension between judo and violence.

\section{Fundamental Principles}

What are, then, the distinctive features of judo? Contrary to popular opinion, and to what is sometimes reported in the general press, but also differently from what the name itself would suggest, the defining and overarching principle is not "making way" or accommodating the partner's initiative to use it against her, nor is judo a purely "defensive" martial art. Here are Kano's words on the matter:

In my youth I studied jujutsu under many eminent masters. Their vast knowledge, the fruit of years of diligent research and rich experience, was of great value to me. At that time, each man presented his art as a collection of techniques. None perceived the guiding principle behind jujutsu. When I encountered differences in the teaching of techniques, I often found myself at a loss to know which was correct. This led me to look for an underlying principle in jujutsu, one that applied when one hit an opponent as well as when one threw him. After a thorough study of the subject, I discerned an all-pervasive principle: to make the most efficient use of mental and physical energy. ${ }^{11}$

This is the principle of Seiryoku-Zenyo, or "maximum efficiency". Its function is complemented by the other pillar of judo, the principle of Jita-Kyoei ("mutual prosperity"). Again, with Kano's words:

As long as we coexist, each member of society and the groups organised within must function in harmony and cooperation with the others. Nothing is more important than living prosperously together. If everyone acts with the spirit of mutual cooperation, each person's work benefits not only himself, but also others, and attaining this together will bring mutual happiness. Activities should not be engaged in simply for selfinterest. Once started, it is only a matter of course that a person will find goodness in harmony and cooperation upon realising that his efforts will increase the prosperity of all. This great principle of harmony and cooperation is, in other words, the concept of Jita-Kyoei, or mutual prosperity for self and others." 12

In the spirit of Olympism and internationalism, Jita-Kyoei is indifferent to national boundaries:

\footnotetext{
${ }^{11}$ Jigoro Kano, Kodokan Judo, 16. At pages 18-19, Kano continues his reasoning after having sketched some practical applications of Seiryoku-Zenyo: "As these examples show, for the purpose of throwing an opponent the principle of leverage is sometimes more important than giving way. Jujutsu also includes other forms of direct attack, such as hitting, kicking and choking. In this respect, the "art of giving way" does not convey the true meaning. If we accept jujutsu as the art or practice of making the most efficient use of mental and physical energy, then we can think of judo as the way, the principle, of doing this, and we arrive at a true definition."

12 Jigoro Kano, "Why it is necessary to advocate the principles of Seiryoku-Zenyo and Jita-Kyoei," Sakko 4/12 (1925), republished on the Kodokan Judo Institute official website: http://kodokanjudoinstitute.org/en/doctrine/word/jita-kyoei/ (accessed June 5, 2018).
} 
I beseech you all to integrate and embrace all these teachings and proclamations, raise the flag of Seiryoku-Zenyo and Jita-Kyoei, notions that are based on the immovable principles of truth, and move forward together with all the people of the world. ${ }^{13}$

The two principles, whose roots can be identified in Japanese and Chinese philosophy ${ }^{14}$, had indeed universal application according to Kano, who saw them as elements of an anthropology — for what concerns the natural sociability at the basis of Jita-Kyoei-and of universal, objective laws.

Kano's claims thus extend further beyond sport regulations and are presented as moral and spiritual truths to inform one's life. At the same time, these principles are meant to be religiously, politically, and to some extent even philosophically neutral ${ }^{15}$, in the sense that they can easily combine with almost any other complete ideological apparatus. The rather indifferent attitude taken by Kano with regards to his being associated to utilitarianism is exemplary in that respect. The "way" was meant to appeal to a diversity of audiences and practitioners worldwide but was also indirectly favored by the logic of minimalism and simplicity. Consequently, judo is neither a mere sport nor a full-fledged ideology, and all the least a quasi-religious system. The correct, moderate understanding of the principles of judo is captured in the following reflections by Kano:

The words jujutsu and judo are each written with two Chinese characters. The ju in both is the same and means "gentleness" or "giving way." The meaning of jutsu is "art, practice," and do means "principle" or "way," the Way being the concept of life itself. Jujutsu may be translated as "the gentle art," judo as "the Way of gentleness," with the implication of first giving way to ultimately gain victory. The Kodokan is, literally, "the school for studying the Way." [...], judo is more than an art of attack and defense. It is a way of life. ${ }^{16}$

Thus, Young is correct in establishing a parallel between "jutsu" and the Greek term techne, as between ethos and the Japanese word do. The objective of judo is not the development of tricks or skills, but the development of the fully functioning and morally mature human being - without going to the point of offering a comprehensive worldview in the way a political or religious system would do.

Thus efficacy, at least in the original philosophy of judo, would not translate into the mere capacity of power to attain a goal, for example a victory in competition, but rather implies the achievement of wholesomeness and well-being. While violence could be instrumental to the formal, it is evidently contrary to the latter.

Furthermore, Kano based judo on a social anthropology which sees the individual's selfrealization as both exclusively possible within and naturally conducive to a harmonious society.

\section{Judo in the World: Present State and Prospects}

If the roots of judo are to be found in Japanese and Oriental history, its trunk is the internationalist construction brought about by Kano and its branches and fruits are

\footnotetext{
13 Ibid.

14 Allen Barry, Striking Beauty, 25-27.

15 Thus, Kano displayed rather casual indifference to the fact that many associated his teachings with those of utilitarian philosophy. see Sasha Cooper and Travis Taylor, "Armbarring the Common Good," in Martial Arts and Philosophy.

16 Jigoro Kano, Judo Kodokan, 16.
} 
constituted by the multiplication of judo national federations and by the worldwide expansion of the sport, which in 1964 made its debut at the Tokyo Olympics.

While no one can deny an overall Japanese dominance even nowadays, since the very 1964 Olympics the triumph of Dutch judo star Antoon Geesink proved the global character of the sport. Japanese Prime Minister Shinzo Abe and Russian President Vladimir Putin are both fans of the sport ${ }^{17}$, with President of Mongolia Battulga Khaltmaa, himself a retired professional wrestler, serving as president of the Mongolian Judo Association. Asia, though, is not the only place where judo is popular, as shown by French record-breaker Teddy Riner-France in general is one of the countries with the highest number of practitioners. Obviously, judo has developed in a peculiar way in each of its new settings ${ }^{18}$.

At the time of the Rio 2016 Olympics there were 389 competitors, a record high, from 136 countries: while worldwide data are more difficult to calculate, the same estimate gives the figure of 24 million $^{19}$. After the European Judo Union, founded in Germany in 1932, the IJF became the main international judo organization: it now comprises 195 national federations and 5 continental unions ${ }^{20}$.

The IJF is constantly revising and updating rules to keep judo an Olympic sport while making it also into a spectator sport, all without sacrificing its rationale and core values. On this road, judo has met and sometimes mingled with martial arts which originated in various parts of the world, and it has continued the transformation to which Kano himself contributed $^{21}$. The relationship judo always had with other Japanese and even Western martial arts has become even more complex with their popularization and institutionalization and with changes in their "social usage" 22. As Carr's article reports, there are ongoing debates about the fidelity to the original project, but judo's vitality and growth are beyond doubt.

\section{Judo and Violence: Conceptual Questions}

How do the lofty principles summarized above apply to the practice and teaching of judo, if at all?

From Kano's words, it seems that the biggest challenge is reconciling efficiency and mutual prosperity: from the discussion over technique/art as opposed to way of life, it would follow that this reconciliation is not only to take place at the level of practicing judo but, and perhaps more importantly, even at the level of teaching it, and at the level of its social repercussions.

Kano needed to develop an efficient art, in the sense that people trained in judo would gain self-defence and attack skills and strength while preserving body integrity. Judo had to distance itself from real-life fighting while keeping its entertaining and attractive character,

\footnotetext{
${ }^{17}$ Frederik Pleitgen and Antonia Mortensen, "Vladimir Putin and Shinzo Abe take time out to enjoy judo," CNN (September 8, 2017), https://edition.cnn.com/2017/09/08/sport/vladimir-putin-russiajudo-shinzo-abe/index.html (accessed June 4, 2018).

18 See for instance Haimo Groenen, L'ukemi, le randori et le kata : une histoire culturelle des méthodes d'entrainement en judo : étude comparée France Belgique de l'entre-deux guerres à la fin des années 1950 (Lyon: University Lyon 1, 2005).

19 Tom McGowan and Henry Young, "Tokyo Grand Slam 2017: Inside the world's most spiritual sport," CNN (December 1, 2017), https://edition.cnn.com/2017/12/01/sport/kodokan-institutenoaki-murata-jigoro-kano-tokyo-2020/index.html (accessed June 4, 2018).

${ }^{20}$ https://www.ijf.org/history (accessed June 4, 2018).

${ }^{21}$ Matt Majendie, "Ripping up the rule book -- how judo reinvented itself for 2018," CNN (March 23, 2018), https://edition.cnn.com/2018/03/23/sport/judo-new-rules-neil-adams/index.html (accessed June 4, 2018).

${ }_{22}$ Jean-Paul Clément, Etude comparative de trois disciplines de combat (lutte, judo, aïki-do) et de leurs usages sociaux (Paris : University Paris 7, 1985).
} 
but it was not to be reduced to gymnastics as well. Finally, it had to bridle individual and collective aggressiveness.

\section{A. Violence in Practicing}

Kano pursued these goals by differentiating between two methods of teaching and practicing judo ${ }^{23}$ : kata (forms), are stylized sequences of techniques, in which both the attacker and the defendant know what is going to happen. In these "plays", virtually everything is allowed, from the same throws permitted in training to defence from gun and knife. Forms exist in all the main modern Japanese martial arts, and it is possible to hold competitions by judging and prizing those executing them most perfectly.

On the other hand, there is randori, (literally "competition," "free sparring"), but in this latter situation the variety of techniques which can be applied is by far more restricted than those recorded in kata or permitted in older jujitsu school. In the Kodokan method, sparring involves both standing and ground techniques: the opponent can be thrown with all kinds of grips (but present rules forbid any catch below the belt and surrounding the chest with both arms), even if the standard grip is applied at sleeve and collar and altered grips such as holding with both hands on one point or side of the opponent's body are allowed only for a short time while attacking. This is to elicit a dynamic combat and for reasons of safety. Intentionally touching the head or face, and especially eyes or mouth, is obviously forbidden, but Kano decided to exclude all strikes and percussions as well after having observed their detrimental effects on health.

The most natural way to win in randori, considering that Kano thought a match should be composed by roughly $70 \%$ standing and 30\% ground fighting, is to throw the opponent with strength, quickness and fluidity, and fully on the back. Control of the technique and the opponent's body are also necessary components for ippon ("full point": originally, a throw or move that could have resulted in $\mathrm{KO}$ ).

While on the ground, the two competitors can win by choking or practicing a joint lock to each other or even by controlling the adversary with her back on the mat for at least 15 seconds for a half point or waza-ari-a 25 second control gives a full ippon, and thus ensures victory. Damages by chokes or joint locks are avoided by requiring all participants to tap immediately on the mat, or simply say that they surrender. Kano and the following developers of his style also eliminated all wrist, spinal and leg locks together with small joint manipulations. Many of these techniques, as for strikes, are still to be found in kata, especially in those devoted to cultivating determination or to training self-defense, but they are not allowed in randori. In combat, only elbow locks are allowed due to their relative safety.

Other techniques have been eliminated during the evolution of judo for their observed effects: in general, any dangerous behavior, such as pivoting on the head to avoid being thrown or while throwing, is forbidden and seriously sanctioned ${ }^{24}$.

Thus, judo differs clearly from karate, which is practiced at a greater distance and is based on blows and strikes. However, the influence of karate is evident in many striking techniques recorded in kata. Aikido and jujitsu also include a different and generally wider range of technique, with aikido normally excluding any form of randori in which the opponents are left without cues on the technique they are to be attacked with. Some forms of aikido do include randori, but usually the defendant can "call" the kind of technique

\footnotetext{
${ }^{23}$ See Haimo Groenen, L'ukemi, le randori et le kata : une histoire culturelle des méthodes d'entraînement en judo: étude comparée France Belgique de l'entre-deux guerres à la fin des années 1950.

${ }^{24}$ Shiai ("fight", "competition") applies all the rules of randori, but the difference is that it is always arbitrated (while for randori it is sufficient to have an opponent) and that the goal is victory and not mere training of technique.
} 
(punching, kicking and so on) they are to guard from. Jujitsu has preserved both a broader array of attacks and randori, but in recent days many athletes eager for a more realistic style of fighting have been drawn to MMA and the like, where a combination of technique from all styles is allowed.

\section{B. Violence in Learning}

In promoting the evolution of judo, Kano was determined to address the bad reputation of jujitsu and other martial arts, and he did so by intervening immediately and most relevantly on the style of teaching. Himself a victim of bullying in childhood, he was acutely sensitive to the fact that "in many dojos surveillance was not sufficient, and the older disciples beat up the younger: thus, jujitsu was disparaged as an occasion of corruptive influence on the juniors" 25 . The addition of the complex philosophical and moral principles that have been recalled so far, and their teaching, represented a major tool to address this defect of preKano jujitsu schools. Other developments are integral to Kano's pedagogical reform as they mirror the equalizing and democratizing interventions he made in schools. For instance, the choice to have all the practitioners dress with the simple, white uniform (judogi, «cloth for judo ») and the system of belt colors. The main divide is between masters, from black belts on, and learners, from white to brown, but weight, age, and belt color categories were introduced for the protection of the novices ${ }^{26}$. Even judo etiquette was standardized with simple but fundamental rules, such as bowing to one another and to the whole community symbolized by the mat.

\section{Violence in Society}

As it has been mentioned while expounding the principle of jita-kyoei, "mutual prosperity" extended, in Kano's intention, to all the people of the world. This dimension of judo has been stressed repeatedly by non-Japanese observers: it is evoked by the image of Kano's casket wrapped in the Olympic flag while descending the Hikawa Maru ${ }^{27}$, and might have contributed to the quick restoration of judo by the Allies authority in post-war Japan. Despite the most difficult to assess, the question on the impact of judo to the prevention and peaceful resolution of conflicts within national communities and beyond, at the international level, is necessarily raised to complete the inquiry over the relationship between judo and violence.

\section{Judo and Violence: Identifying and Researching the Crucial Dynamics}

Since judo has a very complex history, it is composed, partially, by a deep stratification of layers between sport and way of life. And because of its worldwide success, the following analysis of the relation between judo and violence makes no pretense to completeness, especially when considering that the research examples provided rely upon are empirical and are continuously being updated. The present discussion aims at contributing to this progress. However, many tentative answers associated with the analysis of the central questions regarding judo and violence will be discussed, and with the intention of raising new ones. The problem, in philosophy and science, of defining violence, which surfaces in

\footnotetext{
25 Giorgio Sozzi, Impariamo il judo! [Let's learn judo!], (Rome: CONI-FILPJ, 10th edition, year irretrievable), 6 .

26 As it has been mentioned, the introduction of these categories can be read much more critically.

27 Royal Brougham, “A disappointed old man dies. War spoiled his athletic dreams," reported on Judo Info online dojo http://judoinfo.com/kano3/ (accessed June 6, 2018).
} 
much of the literature cited, is also not thoroughly resolved, as violence here signifies simply a breach of bodily integrity, perhaps in line with Norbert Elias' framework ${ }^{28}$.

However, the issue of defining violence is a very complex one. Critical readers of Elias' work have noted that violence is not exclusively the direct attempt at someone's bodily integrity, but can also be subjective, verbal, or even institutional ${ }^{29}$. In this paper I will focus principally on the first conception of violence. Nonetheless, it is evident that this other conception of violence is important to answer regarding questions of violence in judo's education and in its social effects. It is necessary to inquire into these questions as well, but more quantifiable and clear data are accessible concerning the dimension of bodily integrity.

The literature concerning judo and various aspects of health and education is obviously not divided along the three levels of practice, training, and societal impact, but in what follows and to better answer the question of how efficacy is reconciled with violence I will follow the progression randori-judo practice in general-effects beyond and outside the dojo. We now proceed by expounding on a part of the related issues such as: (1) bodily safety, injuries, and the like; (2) discipline and protection of the most vulnerable in the dojo; and, (3) the social, political, and international influence of judo.

\section{A. Safety and Health}

The most blatant and striking form of violence is killing and severely injuring a human being. Martial arts are legitimately accused of tending to this very extreme since their origins are in warfare and the purpose of such activity is subduing, disabling, or eliminating one or more adversaries. Another form of violence to be considered is the accidental injury or even death that occurs as collateral outcome of practicing martial arts, in this case judo, and as either an attacker or defendant.

Since Kano replaced the concept of efficacy in combat with his conception (derived from the Chinese, Japanese, and Western philosophies to which he was exposed) of efficacy as contributing to the development of the individual and to serving society, these are aspects which were immediately and forcefully addressed. Kano set up commissions to study the kind of injures and even the life expectancy of judo practitioners: in fact, already by 1932, he had investigated 12 areas related to judokas' wellbeing, from the effects of warming up and cooling down to dojo hygiene. Life expectancy and the physical and even psychological effects of some techniques were also part of this study ${ }^{30}$.

This interest in the effects of judo on lifespan is easily explained by the possibility of this indicator serving as a proxy for the cumulative impact of small injuries, inflammation, and the like. However, there is no contemporary comprehensive counterpart to Kano's research, while a monograph on the effect of karate on lifespan does exist and has recently sparked

\footnotetext{
28 "Elias characterizes violence as a direct infringement of physical integrity" - Irem Özgören Kınl, "Figurational Analysis of Michael Haneke's Time of the Wolf," in Norbert Elias and Violence, ed. Tatiana Savoia Landini and François Dépelteau (New York: Palgrave Macmillan, 2017), 34. The extended source for discussion of Elias' definition of violence is Jonathan Fletcher, Violence and Civilization: Introduction to the Work of Norbert Elias (Cambridge: Polity Press, 1997), 47-55. At page 47 Fletcher claims that in general "what Elias actually means when he uses the term violence is still unclear" and "violence can only be defined in context". Also, according to Fletcher, Elias first and foremost "refers to physical force when employing the term violence". By taking a Wittgensteinian view on linguistic games and "family resemblances," I do not believe that lack of a clearer definition poses problems for Elias' analysis.

${ }^{29}$ Dominique Bodin, Luc Robène, and Stéphane Héas, "Sport et civilisation: la violence maitrisée?," paper presented at the $10^{\text {th }}$ International Congress of Sport History, organized by the University of Seville and the European committee for sports history, Seville 2005. Accessible online at https://www.cafyd.com/HistDeporte/htm/pdf/2-6.pdf, 3.

${ }^{30}$ See John Stevens, The Way of Judo.
} 
heated debates in the karateka community ${ }^{31}$. Yet, the bulk of studies on judo and health is considerable and wide-ranging.

We can begin in its examination by casting light on an example which apparently falsifies the claim that judo contributes to the reduction of violence. The scandal, emerged in Japan, of numerous children deaths among judo practitioners. According to the New York Times, in Japan, in the thirty years before 2013, 118 children have died while doing judo and 300 have ended up disabled or comatose. The same article goes on to explain that "The statistics have no parallel in other developed nations where the sport is popular". Indeed, neither France nor the US, despite a number of practitioners comparable to Japan, have recorded any death or traumatic brain injuries for children in decades. According to doctor Robert Nishime, "the Japanese cultural trait of not giving up, gaman, might explain why a concussion, which can be subtle, could be played down by the instructor or the child." Another explanation offered in the article for Japan's uniquely bleak figures is that corporal punishment is still in use and approved of by coaches and society. If the explanation regarding the "not giving up" cultural trait is sound, then these appalling deaths would have more to do with karoshi ("overwork to death") than to judo itself. This seems to be demonstrated by the very different situation of other countries. Although, the death and permanent injury rate of children aged 12-17 practicing judo in Japan is five times higher than that of any other sport ${ }^{32}$, while gaman would supposedly affect marathonists and boxers as well.

Apparently, the safety of judo when controlling for such cultural traits would be demonstrated by the comparative rate of all injuries. In a study by Mark Fischetti ${ }^{33}$ of the 2008 summer and 2010 winter Olympics, judo ranked 19 $9^{\text {th }}$ for the number of injuries encountered by athletes $\left(10^{\text {th }}\right.$ if one considers summer sports only) with $11 \%$, roughly on pair with baseball. When considering the number of injuries preventing athletes from competing or training, however, judo did slightly worse, ending in the $8^{\text {th }}$ position with a percentage of about $6 \%$. Thus, it seems that judo has a relatively higher rate of serious injuries compared to overall injuries. To put this figure in context, it might be added that football and taekwondo were second and third respectively, with both reaching higher than $15 \%$ serious injury rate, and football faring worse than the Korean martial art with its overall injury rate at more than $30 \%$, (while the latter marked $27 \%$ total injuries). Even the most dangerous sport of the survey, cross snowboard, has lower rates of serious injuries $(14 \%)$ while scoring 35\% overall injuries among the Olympians. The other fighting sport with more many injuries than judo was boxing, but the judo/taekwondo ratio is approximately 1:3 for serious injuries preventing training or competition and 2:5 for all injuries. Wrestling was apparently slightly safer than judo. It is true that these numbers are still considerable when thinking that Olympic elite athletes are obviously provided with

\footnotetext{
${ }^{31}$ Jason Arstrong and Sarven Mclinton, Karate Styles: Surprising Links to Shortened Lifespan, (Published online at lulu.com: The Traditional Japanese Karate Network 2017). Note that the study includes a section, however brief, on the comparison between karate and other martial arts, including judo.

32 Daiel Krieger and Noriko Norica-Panayota, "Japan Confronts Hazards of Judo," The New York Times (April 17, 2013). According to the Japan Times, the UK joined France and the US in denying any casualty or permanent disability resulting from the practice of judo in recent decades. See Mike Burke, "108 school judo class deaths but no charges, only silence," (26 August 2010).

33 Mark Fischetti, "Olympic Hurtfuls," Scientific American (August 1, 2012): 92. General difficulties which affect this no differently than any other similar study (defining what counts as an injury, dealing with different reporting rates in different sports, and other differences such as length of competitive bouts) still do not seem to invalidate the report since aquatic sports are consistently at the lowest end of the chart while winter and fighting sports are among those with the worst figures, as intuition and reasoning would suggest. Thus, even if it seems more dangerous than about 30 other Olympic sports, judo, when done in proper conditions, is relatively safe.
} 
state-of-the-art equipment, assistance, and injury-prevention and recovering training and techniques, but it is also true that at the Olympic level athletes push their limits to the extreme.

Similar results are discussed in a study by Thomas W. Woodward, who reminds the reader that "Surprisingly, a large survey demonstrated that martial arts are safer than many other sports, including football, basketball, and wrestling." ${ }^{4}$ After considering the psychological benefits on attention, aggressiveness, and sleep disorders also, Woodward concludes that "Physicians may consider recommending martial arts to patients of all ages who are interested in exercise." 35 Woodward's observations converge with Fischetti also on judging taekwondo as the most dangerous martial art, even when including non-Olympics arts such as karate.

Furthermore, a systematic review ${ }^{36}$ of 28 articles, 4 of which devoted to judo, details the benefits of judo, among other hard martial arts. These include greater balance ability, faster reaction time to peripheral visual stimuli and a delay in visual acuity decline, better dynamic visual acuity than experiment participants of the same age ${ }^{37}$, greater bone and hand grip strength, greater muscular strength and endurance, and reduced hip impact, with higher bone mineral density being observed only for male judo practitioners, and increases in heart rate in beginner judo participants ${ }^{38}$. In conclusion, the review also confirms the lower rate of serious injuries in traditional martial arts compared to other sports, but it acknowledges the relative scarcity and the many methodological weaknesses of the sources: to name but one, observations are usually restricted to groups of athletes and the aim of most research is to improve performance rather than health. The article supports the necessity to study the associations between practicing martial arts and long-term morbidity and mortality rates ${ }^{39}$.

\section{B. Pedagogics}

The pedagogics of judo is the activity and practice of transmitting judo from master to student, from student to student, and from master to master. My estimate is that the problem of the conflict between efficiency and violence at this level is unreasonably underestimated when compared to Kano's original and acute awareness of, for example, the importance of surveillance to avoid hazing.

The problem emerges at its most horrific level in the articles mentioned in the opening of the previous section, which report examples of Japanese judo teachers chocking their young students unconscious to punish them for being late or for skipping a session. Another remarkable example would be the scandal generated by champion Shoei Ono, who despite his talent was severely disciplined after ordering younger practitioners to slap freshmen on their faces ${ }^{40}$.

Given the severity and frequency of these episodes, one is surprised by finding in the literature frequent references to ways to quickly transmitting techniques and optimizing

\footnotetext{
${ }^{34}$ Thomas W. Woodward, "A Review on the Effects of Martial Arts Practice on Health," Wisconsin Medical Journal 108/1 (2009): 40-43. Evidence for the safety of martial arts is taken from Birrer RB. "Trauma epidemiology in the martial arts: the results of an eighteen-year international survey," American Journal of Sports Medicine 24/6 (1996): 572-579.

35 Thomas W. Woodward, "A Review on the Effects of Martial Arts Practice on Health" :42-43.

36 Sandra Origua Rios, Jennifer Marks, Isaac Estevan \& Lisa M. Barnett (2018) "Health benefits of hard martial arts in adults: a systematic review," Journal of Sports Sciences 36/14 (2018): 1614-1622.

${ }^{37}$ Ibid., 1617.

38 Ibid., 1618.

39 Pp. 1618-19.

40 "World judo champion Ono suspended for assaulting teammate," The Japan Times (11 September 2013).
} 
training cycles, but almost no mention of the risk of hazing and other misbehaviors by instructors and mates.

This reluctance does not match the explicit and vigorous tackling of such problems exemplified by Kano, which contributed greatly to the evolution of jujitsu and judo and to their worldwide diffusion.

Some interesting and exceptionally critical studies, while not directly considering the issue of violence, raise at least the question of the consideration of the children public and the reduction of gender stereotypes ${ }^{41}$. Inclusion of women was indeed among the concerns of Kano, notwithstanding the obvious limitations posed by social conceptions of the time.

Also, the way violence is constrained in and by a teaching informed by humanistic and democratic values is an essential bridge between the reduction of bodily harm in judo contests and sparring and the more general effects of judo, especially on aggressiveness, which we now turn to consider.

\section{The Contribution of Judo to Society}

Common sense, traditional assumptions, and a significant amount of studies are witness to the positive effect of sport in general for psychology and control of emotions. This conventional view is confirmed, not without caveats and reservations, in a white paper published by the United States Judo Federation ${ }^{42}$. The authors analyse a set of peerreviewed studies in English: they admit the number of scientific sources is limited by the fact that, while studies abound, their methodology is often questionable. However, they conclude from the review of their selection that "the available evidence is strongly suggestive of the positive effects of judo practice" 43 . They report positive results for the mental and physical wellbeing of handicapped and high-risk children, including the reduction in aggressive tendencies, and some physical improvements which were not detected in the studies recalled in the previous section. Even if "Collectively these findings provide scientific evidence suggestive of the positive effects of judo" 44 , the limits of this "suggestion" are shown by the scarcity of participants observed compared to the millions of judo practitioners, by their being a pre-selected group, and by the specific intervention which included an exemplary judo class and the offering of mentoring to parents. Even if no one would contest that mentoring and psychological couching fit well with the traditional function and dynamics of judo, they are rarely available in real-world practice. Finally, despite its unquestionable reliability and the professionality of the researchers involved, the USJF cannot be considered neutral with regards to the results of the review.

A more specific but also more nuanced view is offered by Éric Reines and Jacque Lorant ${ }^{45}$, whose results demonstrate a diminution in aggressiveness and a growth in selfcontrol only for female participants. Indeed, even the author of the USJF white paper admit that evidence on aggressiveness reduction is mixed and inconclusive. This contrast is addressed by a very recent and wide-ranging study by Anna Harwood, Yuri Rassovsky, and Michal Davidor, who conclude that "martial arts have a potential to reduce externalizing

\footnotetext{
${ }^{41}$ Samuel Julhe, "Le judo et l'enfant. Regards et pratiques d'enseignantes," Staps 2 (2012) : 121-137.

42 USJF, "The Psychological and Behavioral Effects of Judo" (4 January 2004), published online at http://usjf.com/sites/usjf.pwcstores.com/files/imagelibrary/uploads/2013/08/Judo-Review.pdf accessed June 5, 2018).

${ }^{43}$ Ibid., 10.

${ }^{44}$ Ibid., 11.

45 Éric Reynes, Jean Lorant, "Judo, agressivité et maittrise de la colère : étude longitudinale chez des enfants de 8 ans," Staps $1 / 60$ (2003) : 93-105.
} 
behaviors in youth, although further research is needed to determine the mechanisms of change and specify the most relevant population groups for targeted interventions." 46

Other studies reiterate the point that "even though a considerable amount of research on social-psychological outcomes of martial arts practice has been conducted over the years, to date, it has not brought clarity in the existing duality regarding the possible effects of martial arts involvement." 47 The authors go on to propose "that a better understanding can be provided if specific influential factors are taken into account in future research (i.e., participants' characteristics, type of guidance, social context and structural qualities of the sport)" 48 , which resonates with the intuitions voiced previously on the role of the kind of training and education provided. In another study on the role of mediating factors, the authors conclude that: "The fact that differences in these mediating factors can be identified indicates that in future research these and possible other mediating factors should be considered when trying to determine social-psychological outcomes of MA\&CS [martial arts and combat sports]." ${ }^{49}$ Given the negative impact of the behaviors recalled above, one would strongly suspect that the conditions of training and the style of coaching would be mediating factors as influential as the participants' social background or their psychological profile.

A complete exploration of the topic would at this point consider the studies concerning judo as a tool of international relations and diplomacy, and its contribution to the emergence of a global culture. As it has been stressed, this dimension was a foundational component of the martial art and sport devised by Kano as a unique and coherent creation. People have indeed discussed "political judo"50, "judo diplomacy"51 and "the bow as foreign policy" 52 . There is no doubt the international and political dimension that characterized judo from its very origins, as the 1879 public demonstration to US President Ulysses Grant shows, is still lively. Restriction of violence against any human being, coupled with understanding and friendship between all the peoples of the world, is surely among the most fundamental judo ideals, even if the impact and efficacy of judo at this level is practically very hard to measure.

\section{Conclusions and Suggestions for Further Research}

\section{A. Judo as a Way of "Civilizing" Violence?}

Judo has also already been explored, thoroughly and recently, from a viewpoint specifically informed by figurational sociology ${ }^{53}$. Figurational sociology is, in general terms, an approach

\footnotetext{
46 Anna Harwood, Michal Lavidor and Yuri Rassovsky, "Reducing aggression with martial arts: A meta-analysis of child and youth studies," Aggression and Violent Behavior 34 (2017): 96-101.

47 Jikkemien Vertonghen, Marc J. Theeboom, "The Social-Psychological Outcomes of Martial Arts Practise Among Youth: A Review," Sports Science \& Medicine 9/4 (2010): 528-537.

48 Ibid.

${ }^{49} \mathrm{M}$. Theeboom, J. Vertonghen, Pieter Willy, "Mediating factors in martial arts and combat sports: an analysis of the type of martial art, characteristics, and social background of young participants," Perceptual and Motor Skills 118 (2014): 41-61.

${ }^{50}$ Jill Dougherty, "How Vladimir Putin's political judo floored his opponents," CNN (January 5, 2017).

51 "Leading article: A bout of judo diplomacy," The Independent, 3 August 2012.

52 David Matsumoto, "Respect and International Affairs: Mutual Welfare and Benefit and the Bow as Foreign Policy," David Matsumoto, Presentation delivered at the 2008 Budo Symposium at the National Institute of Fitness and Sports in Kanoya, Department of Traditional Budo and Sport Culture. Accessible online at http://budo2008.nifs-k.ac.jp/pdf/matsumoto_e.pdf.

53 Raúl Sánchez-García, “The development of Kano's judo within Japanese civilizing/decivilizing processes,” Asia Pacific Journal of Sport and Social Science 5/2 (2016): 108-119.
} 
which is preoccupied with capturing the entire dynamic of social phenomena, and thus consider them processes rather than static objects. In order to appreciate the complexity of these ever-evolving social configurations, figurational sociology cannot confine itself to disciplinary boundaries and is particularly committed to the analysis of the interdependent evolution of ideas, institutions and practices in history.

A key conception of Elias' figurational sociology is the process of civilization. This theory holds, once again in very general terms, that the more complex and diversified social life becomes, the higher degree of social control is internalized by individuals. In particular, the formation of the modern state and of the civil culture which accompanies it would be characterized by the progressive reduction of violence and other physical and emotional spontaneity, in parallel with the growth of the state's monopoly over conflicts and the sedimentation of culture, good manners, and emotional restraints in the individual and collective psyche.

In the light of what has been expounded over and claimed in the first part of this study, the trajectory of judo seems to confirm the soundness of Elias' and Dunning's theoretical framework. The sport was developed during the consolidation of Japan as a modern state, thanks to foreign influence, especially by the American and British who were starting the systematization of modern sports at the same time. In the history of judo and Japan, the same processes of secularization, modernization, institutionalization, bureaucratization and democratization that Elias and Dunning trace in other sports are evident. Given Kano's pedagogical vocation, and judo's origin from warfare and a period of constant civil war, the creation of Judo Kodokan as a form and institution of education is exemplary of the role of sports in the civilizing process. The institutionalization and the rational measurement applied to judo did not only parallel those happening in the West and worldwide but were strictly intertwined with them given Kano's belonging to the IOC.

In judo, the "controlled and enjoyable decontrolling of restraints on emotions" 54 , which according to Elias and Dunning is a crucial function of modern sports, is not only present, but central. Kano selected for competitions only those techniques which could be safely executed at full force. And every judo practitioner knows the blissful, however rare, sensation of the perfect ippon, in which instinct, technique, and the flow of rational choices coincide to obtain a perfectly natural and yet artificial explosion, an accidental and yet construed momentum which gains victory before one can even be conscious of it. The classic teachings to which a judoka is exposed since childhood, or since the beginning of practice, is that control of that explosive gesture is indispensable to score a full point. An even rarer but no less explicative part of this control, exemplified in the kata, is the ecstatic pause in which tori ("the one who has executed the technique") rests still while becoming aware of her or his own achievement, and while the energy of the action reverberates as in an echo. This mental condition of controlling body movements and mastering chaos is defined in Japanese martial arts by the poetic term zanshin ("remaining heart").

\section{B. Review of the Established Results}

In conclusion, it would be reductive to claim that the control of violence occupies a central role in judo: judo consists in the reduction of violence. Not only the kind of violence which was allowed in previous forms of jujitsu, but also violence understood as dissipation of energies, as activities which destruct rather than edify the individual and society. In this sense, the two foundational principles of "best use of energy" and "mutual prosperity" are

\footnotetext{
${ }^{54}$ Norbert Elias and Eric Dunning, Quest for Excitement: Sport and Leisure in the Civilizing Process, (Oxford: Blackwell 1986), 65 and following, 96. Cited and discussed in Stephen Mennell, "The Contribution of Eric Dunning to the Sociology of Sport: The Foundations", Sport in Society 9/4 (2006) : 514-532.
} 
converging, and not opposite, since the goal of judo as a way is broader than that of jujitsu as a collection of techniques, and it consists in becoming a physically, psychologically, and socially healthy individual ready to interact harmoniously with others. Winning a fight or becoming a sport champion is not by itself the objective of judo as defined by Kano and by the institutions inspired with his thought, especially the Kodokan and the IJF.

In this sense, the minimization of violence is the maximization of efficacy.

At the level of the sport's matches, as Fischetti and other authors show, Kano had succeeded in creating an exceptionally safe martial art with a percentage of injuries which is two to three times less than soccer. This is astonishing if one considers that the aim of one sport is to throw an inflated ball in a net, and the aim of the other is to throw another person's back forcefully on the ground, or to control the person by grappling, strangling, and applying elbow locks. The reduction of violence here is achieved by a number of means, from continuous revision of the rules to the limitation of employable techniques and development of safer equipment, beginning with the mat. To these, one must add the benefits of judo to fitness: both those which are shared with sport and physical activity in general, and those which are more specific. An overarching study of life expectancy and morbidity, as suggested in the literature, is needed to confirm the anecdotic evidence provided by those, such as Ichiro Abe and Jack Earn, who still practice past ninety.

On the basis of the literature quoted and accessed, the embarrassing problem of violence in the dojo-masters and fellow practitioners attacking physically and/or verbally or otherwise bullying beyond and against judo rules and spirit-seems not sufficiently explored. However, Kano was explicit in naming it as one of the reasons that lead him to establish a new art from jujitsu, and the whole structure of instruction he devised-from dress code to bowing and the ordered progression of techniques taught-is devoted to creating a safe, enjoyable, equal, open, and democratic dojo. My conclusion is that researchers and practitioners should pay more attention to this aspect, independently from the objective of training more successful agonistic competitors which is presently the privileged focus. Kano was a pedagogue and a school reformer: his creature cannot neglect pedagogics and correct teaching and training.

The methodology through which it is transmitted can also inform the third way in which judo tackles violence, that is, its contribution to society even outside the mat and dojo. From school classes to international relations, judo is meant to be a source of harmony and skill for conflict management, self-control, empathy, self-esteem, capability of defending oneself and others when physically and symbolically aggressed. Even if there are solid scientific researches showing the positive effects of judo in reducing and managing aggressiveness, evidence is mixed and the number of studies do not reflect the huge global popularity of the sport. Also, styles of teaching and coaching should be considered among the mediating factors. New and deeper research is thus needed.

The philosophical sophistication of judo transpires from its own core principles and their relations with the history and thought of Western and Eastern societies. It can be connected to the ancient Chinese Tao Te Ching as well as to utilitarianism, and both are useful to understand the relation between judo and violence.

Now that judo has become a worldwide cultural and part of sports heritage, and that it has included personalities such as US President Theodore Roosevelt and two generations of Canadian Prime Ministers, Pierre and Justin Trudeau, in its hall of fame, one can question whether the discipline is still the same that was created by Kano. In his article recalled above, Carr claims that contemporary champions are as indifferent to moral principles as ancient fighting masters at time of Japan's feudal civil wars. In that case, the principle of efficacy would be redefined as the quality of a technique, training, or behaviour that guarantees victory, and judo could be as violent and pre-civilized as martial arts were back then. Indeed, and most sadly, Carr's insight is proved right by the emergence of many neo- 
barbaric practices brought about by views of agonistic judo which are divorced from Kano's philosophy and really define efficacy as the capability to win no matter what it takes. One of the most telling exempla would be the extreme expedients to cut weight before competition at the cost of health and safety. ${ }^{55}$

But the research discussed here inspire at the least the doubt, the hope, and the possibility that judo retains its concern with human flourishing in its widest and complete acceptation, and thus violence would be as inimical to it as it was in the philosophical and mythical creeds which inspired $\mathrm{Kano}^{56}$.

If this original intuition will continue to be the philosophy that marks future developments of judo, despite all appearances of bruises, occasional injuries, and even despite the gravest violations of its code, judo and violence would remain in the same relation as gold and raw materials in the metaphor suggested at the beginning: on the surface, hardly distinguishable, but incompatible in essence and incomparable in value.

\section{Acknowledgements}

I wish to thank Prof. Raphaël Verchère and the Pbilosophical Journal of Conflict and Violence for the interest taken in this article. I also thank the two anonymous reviewers for their appreciation and critique, and especially for many useful hints and suggestions.

Sincere acknowledgements are also due to Judo Body Park CUS Bergamo ASD (especially on the occasion of the $30^{\text {th }}$ anniversary of the foundation of the dojo), Judo Club Pavia, Judo-Club de Genève, and to the FIJLKAM among other for having nourished the passion and knowledge which made this research possible.

Finally, I thank my colleagues from the PhD School of Philosophy and Human Sciences at the University of Milan, in particular Eugenio Petrovich and Flavio Baracco, for having first suggested to write on philosophy and martial arts.

\section{References}

Arena, Leonardo Vittorio. Samurai: Ascesa e declino di una grande casta di guerrieri. Milan : Mondadori, 2002. Kamikaze : The Epic of Suicidal Warriors. Milan : Mondadori, 2003. - Il pennello e la spada : la via del samurai. Milan : Mondadori, 2013.

Arstrong, Jason and Sarven Mclinton. Karate Styles: Surprising Links to Shortened Lifespan. Published online at lulu.com: The Traditional Japanese Karate Network, 2017.

Barnett Lisa M., Isaac Estevan, Jennifer Marks, Sandra Origua Rios. "Health benefits of hard martial arts in adults: a systematic review." Journal of Sports Sciences 36/14 (2018): 1614-1622,

\footnotetext{
55 See the deep analysis and critique of such practice in Michaël Hilpron, De "faire du judo" à "faire judo" : approche ethnographique d'une pratique de haut-niveau par la culture matérielle (Orléans : University of Orléans, 2012). Hilpron also presents an interesting discussion of efficiency in judo in "L'appropriation du judo : d'une voie de la souplesse à l'efficience incarnée", Staps 4/98 : 143-156.

56 "Kanō tells another story that attributes the origin of jujitsu to a physician named Akiyama, who went to China to study medicine. He returned having learned a fighting art that he tried to teach others, but all his students were unsatisfied and deserted him. Akiyama then retreated to Tenjin Shrine in Tsukushi and worshipped there for a hundred days, after which time a new fighting art was finally revealed to him. During a snowstorm he observed a willow tree whose branches were covered in snow. Unlike the pine tree, which stood erect and broke during the storm, the willow yielded to the weight of the snow on its branches but did not break under it. He realized that martial arts must be practiced in the same way. So he named his school Yōshin-ryū, the Spirit of Willow school.” Allen Barry, Striking Beauty, 27.
} 
Barry, Allen. Striking Beauty: A Philosophical Look at the Asian Martial Arts. New York: Columbia University Press, 2015.

Birrer, RB. "Trauma epidemiology in the martial arts: the results of an eighteen-year international survey," American Journal of Sports Medicine 24/ 6 (1996):572-579.

Bodin, Dominique, Luc Robène, and Stéphane Héas. "Sport et civilisation : la violence maitrisée ?". Paper presented at the $10^{\text {th }}$ International Congress of Sport History, organized by the University of Seville and the European committee for sports history. Seville 2005. Accessible online at https://www.cafyd.com/HistDeporte/htm/pdf/26.pdf (last accessed November 25, 2018).

Brougham, Royal. "A disappointed old man dies. War spoiled his athletic dreams," reported on Judo Info online dojo http://judoinfo.com/kano3/ (accessed May 20, 2018).

Burke, Mike. "108 school judo class deaths but no charges, only silence". Japan Times, August 26, 2010.

Carr, Kevin Gray. "Making Way: War, Philosophy and Sport in Japanese Judo.". Journal of Sport History 20/2 (1993): 167-188.

Clément, Jean-Paul. Etude comparative de trois disciplines de combat (lutte, judo, aïki-do) et de leurs usages sociaux. Paris : University of Paris 7, 1985.

Dougherty, Jill. “How Vladimir Putin's political judo floored his opponents”. CNN January 5, 2017.

Dunning, Eric, Norbert Elias. Quest for Excitement: Sport and Leisure in the Civilizing Process. Oxford: Blackwell, 1986.

Fischetti, Mark. "Olympic Hurtfuls." Scientific American (August 1, 2012): 92.

Fletcher, Jonathan. Violence and Civilization: Introduction to the Work of Norbert Elias. Cambridge: Polity Press, 1997.

Green, Thomas ed. Martial Arts of the World: An Encyclopedia. Volume I. Santa Barbara, Denver and London: ABC-CLIO, 2001.

Groenen, Haimo. L'ukemi, le randori et le kata : une histoire culturelle des méthodes d'entraînement en judo : étude comparée France Belgique de l'entre-deux guerres à la fin des années 1950. Lyon: University Lyon 1, 2005.

Harwood, Anna, Michal Lavidor, Yuri Rassovsky. "Reducing aggression with martial arts: A meta-analysis of child and youth studies.”. Aggression and Violent Behavior 34 (2017): 96101.

Henshall, Kenneth. A History of Japan: From Stone Age to Superpower. London : Palgrave Macmillan 2012.

Hilpron, Michaël. De "faire du judo» à «faire judo» : approche ethnographique d'une pratique de hautniveau par la culture matérielle, Orléans : University of Orléans, 2012.

"L'appropriation du judo : d'une voie de la souplesse à l'efficience incarnée.". Staps, 4/98 (2012) :143-156.

International Judo Federation, https://www.ijf.org/history/judo-corner (accessed May 20, 2018).

Judo Channel (http://www.judo-ch.jp/english/kanou_life/profile/index02.shtml (accessed June 4, 2018).

Juhle, Samuel. "Les Pratiques Martiales Japonaises en France. Institutionnalisation des disciplines et professionnalisation de l'enseignement." Actes de la recherche en sciences sociales 4/179 (2009) : 92-111.

“Le judo et l'enfant. Regards et pratiques d'enseignantes. » Staps 2 (2012) :121-137.

Kano, Jigoro. "Jujitsu and the origin of judo." Translated by Thomas Lindsay, in Transactions of the Asiatic Society of Japan 15 (1887). Republished on Judo Info Online Dojo: http://judoinfo.com/kano6/ (accessed May 20, 2018).

"Why it is necessary to advocate the principles of Seiryoku-Zenyo and Jita-Kyoei." Sakko 4/12 (1925). Republished on the Kodokan Judo Institute official website: 
http://kodokanjudoinstitute.org/en/doctrine/word/jita-kyoei/ (accessed May 30, 2018).

. Kodokan Judo. London, New York, Tokyo: Kodansha International, 1986.

Kınl, Irem Özgören. “Figurational Analysis of Michael Haneke's Time of the Wolf'. In Norbert Elias and Violence, ed. Tatiana Savoia Landini and François Dépelteau. New York: Palgrave Macmillan, 2017.

Krieger, Daiel, Noriko Norica-Panayota. "Japan Confronts Hazards of Judo." The New York Times. 17 April 2013.

Liu, Chang, Kyungwon Jung, Fumiaki Shishida. “A Technical analysis of Seiryoku zen’yo Kokumin taiiku-From a Karate and Chinese martial arts perspective as it affected Kano Jigoro," Journal of Martial Arts Anthropology 16/1 (2016): 1-10.

Maddaloni, Gianni. La mia vita sportiva. Milano: La Comune, 2010.

Matsumoto, David. "Respect and International Affairs: Mutual Welfare and Benefit and the Bow as Foreign Policy." Presentation delivered at the 2008 Budo Symposium at the National Institute of Fitness and Sports in Kanoya, Department of Traditional Budo and Sport Culture. Accessible online at http://budo2008.nifs-

k.ac.jp/pdf/matsumoto_e.pdf, (accessed June 2, 2018).

Mifune, Kyuzo. Canon of Judo. Tokyo: Seibundo-Shinkosha Publishing and Co., 1958.

Majendie, Matt. "Ripping up the rule book-how judo reinvented itself for 2018." CNN (March 23, 2018). https://edition.cnn.com/2018/03/23/sport/judo-new-rules-neiladams/index.html (accessed May 30, 2018).

McGowan, Tom, Henry Young. “Tokyo Grand Slam 2017: Inside the world’s most spiritual sport." CNN (December 1, 2017). https://edition.cnn.com/2017/12/01/sport/kodokan-institute-noaki-murata-jigorokano-tokyo-2020/index.html (accessed June 4, 2018).

Mennell, Stephen. "The Contribution of Eric Dunning to the Sociology of Sport: The Foundations." Sport in Society 9/4 (2006): 514-532.

Mortensen, Antonia, Frederik Pleitgen. "Vladimir Putin and Shinzo Abe take time out to enjoy judo." CNN (September 8, 2017).

https://edition.cnn.com/2017/09/08/sport/vladimir-putin-russia-judo-shinzoabe/index.html (accessed May 30, 2018).

Pontecorvo, Marco. L'oro di Scampia. Rome, Rai Cinema, 2014.

Priest, Graham, Demon Young (eds). Martial Arts and Philosophy: Beating and Nothingness. Chicago and LaSalle: Opencourt, 2010.

Sánchez-García, Raúl. «The development of Kano’s judo within Japanese civilizing/decivilizing processes. » Asia Pacific Journal of Sport and Social Science 5/2 (2016): 108-119.

Sozzi, Giorgio. Impariamo il judo!. Rome: CONI-FILPJ, 10th edition, year irretrievable.

Stevens, John. The Way of Judo: A Portrait of Jigoro Kano and his Disciples. Boston and London: Shambhala, 2013.

Theeboom, Marc J., Jikkemien Vertonghen. "The Social-Psychological Outcomes of Martial Arts Practise Among Youth: A Review.” Sports Science \& Medicine $9 / 4$ (2010): 528-537.

Theeboom, Marc, Jikkemien Vertonghen, Pieter Willy. "Mediating factors in martial arts and combat sports: an analysis of the type of martial art, characteristics, and social background of young participants." Perceptual and Motor Skills 118 (2014): 41-61.

United States Judo Federation. "The Psychological and Behavioral Effects of Judo", 4 January 2004. Published online at http://usjf.com/sites/usjf.pwcstores.com/files/imagelibrary/uploads/2013/08/JudoReview.pdf (accessed June 4, 2018).

Watson, Brian N. The Father of Judo: A Biography of Jigoro Kano. New York: Kodansha Amer. Inc., 2000. 
Judo Memoirs from Jigoro Kano. Bloomington: Trafford Publishing, 2008.

"World judo champion Ono suspended for assaulting teammate." The Japan Times. 11 September 2013.

Woodward, Thomas W. "A Review on the Effects of Martial Arts Practice on Health." Wisconsin Medical Journal 108/1 (2009): 40-43. 